\title{
Insights from an editor's journey: an interview with Gert Biesta
}

This is an earlier version of the published article. Please use the reference below to quote this article:

Teschers, C. (2015). Insights from an Editor's Journey: An interview with Gert Biesta.

Educational Philosophy and Theory, early online publication,

http://dx.doi.org/10.1080/00131857.2015.1069032 


\title{
Insights from an editor's journey: an interview with Gert Biesta
}

\author{
Christoph Teschers \\ New Zealand Tertiary College
}

Gert J. J. Biesta is a widely known and respected scholar in the field of education. He has published a large number of articles, books, chapters and other work. From 1999 to 2014 he was Editor-in-Chief of the journal Studies in Philosophy of Education published by Springer. Before that, he was involved in the Dutch Education Journal over a three-year period as Editor-in-Chief and member of the editorial board. Biesta has also co-edited and supported a number of other educational journals, including open-access and online journals. Since January 2015, he is a member of the Netherlands Education Council 'Onderwijsraad' and Professor of Education in the Department of Education at Brunel University, London.

This interview with Gert Biesta touched on a wide range of topics, and due to the interactive and emerging nature of an interview setting, the initially-anticipated scope nearly doubled as questions and answers unfolded. This article is a selection of some of the topics that have been discussed, with a focus on: (i) changes and developments in journal publishing over the last 15 years, including online publishing, open-access journal options and the increased number of publications in the field; (ii) considerations for early career academics and emergent researchers in relation to publishing; and (iii) questions about journal rankings, quality control, and the peer-review process. Biesta shared his thoughts based on his vast experience in the field and his international experience, having worked at universities in various European countries and with a wide range of scholars around the globe. This interview took place during the Philosophy of Education Society of Australasia (PESA) Conference held in December, 2014 in Hamilton, New Zealand.

Christoph: Gert, thank you very much for agreeing to this interview. Let me start with the first question: what significant changes have you seen in publishing during your academic career over your $15+$ years as editor, and maybe during your involvement beforehand as well?

Gert: I think the main change I have seen is the rise of electronic publishing. When I started out on my own academic career, things were paper based, and when I started as an editor of the Studies' Journal, it also only existed on paper. Then, after a few years, more and more came on-line. I actually don't remember exactly, but I guess for about 10 years now it has been fully online. A major change there is that the Journal has become accessible to a much larger audience. When I took over the Journal, it had about 400 subscriptions worldwide, which was at the lower end of the spectrum, and over the past five years, I think, we have annually about sixty or seventy thousand downloads. That shows that the visibility has very much increased as a result of being available as an electronic journal and it being sold by the publisher as part of a package. Publishers do not negotiate individual journals with libraries, but they say to a library: you can get the humanities package or the social science package and a couple of hundred journals from Springer, for example, for one price. That has also 
benefited, you could say, the more marginal fields, like philosophy of education. They are part of a package with mainstream journals.

Christoph: So you would say that the packaging for philosophy of education specifically is more beneficial than individual subscriptions.

Gert: For what you could call niche areas, compared to some more mainstream areas, the packaging has been very beneficial, because, I can imagine, if a librarian needs to make a decision whether or not to subscribe to a single philosophy of education journal, they might not be inclined to do that. But if they just get the package with the journal in it, then they don't really think about that because they want the mainstream journals and the package.

Christoph: How has the move to electronic publishing changed the landscape as compared with the traditional paper-based form?

Gert: I would say that for small areas, like philosophy of education, this made it much more accessible and that translates into the number of downloads. So, we see that there are a large number of people who actually download the papers. They make an effort to get hold of them.

Christoph: Did this trend have an impact on the academic work or on academic writing that was getting published?

Gert: Not that I've noticed. I think the only other sort of major development that I've seen is that more and more people are forced to write academic papers. That would be the polite way of saying that not only has higher education expanded in terms of institutions, but within the institutions, more and more people are now required to publish. This has dramatically increased the number of papers available. In the Journal, I've seen a steady increase of the number of submitted manuscripts. I would say steady, so not spectacular, but over 10 years it has maybe tripled. When you look more widely at a number of new journals that have started up, we see that the overall volume of academic publishing is growing exponentially, simply because places that used to be focusing on teaching now also require that people publish. I'm also beginning to see the impact of, for example, $\mathrm{PhDs}$ by publication, which has become quite popular in a number of European countries. What a lot of students do is that they start with writing literature reviews. I get significantly more of that kind of papers, which are really underdeveloped but they are the effect of some of the changes in the academic world.

Christoph: So do you think that these literature review papers should be accepted to support the development of this $\mathrm{PhD}$ stream or do you see this $\mathrm{PhD}$ stream as a problem for publishing, as it creates more work with lower quality?

Gert: I do see it as a problem, because to write particularly good review articles actually requires that you really understand the field. Most of those papers that I see are not very mature, but they do end up on the desks of editors.

Christoph: OK, we have touched on a couple of points already that we are going back to in a minute, but let's go to the second question: what do you see as the future of academic publishing in terms of hardcopy and softcopy, and maybe other aspects you might know of?

Gert: My sentiment is that, at least for my journal and for journals more generally, hardcopies have become quite irrelevant. I still get a hard copy of my journal and I know it is 
in some libraries, but most of it is online. So, I expect that at some point this will change and publishers might go to print on demand. So that's my prediction.

I don't think that this is necessarily bad, although I do think that the reading habits of people have changed. I still remember the time when you would get a copy of a journal that you subscribed to and you would read the whole copy to see what was going on in the field. This is impossible to do now, given the volume - but I also don't think that that's how people look at journals. So in that way, it is affecting the way in which we read and even the identity of the journal changes. The journal is a website where you can download papers, and I guess that for the moment that is what academic publishing will look like.

Christoph: Do you think that this might have an impact on how emerging academics in particular will perceive the field of education? So, might there be a stronger specialization in certain areas because they only find the articles they are looking for, they might not find articles of areas that are discussed in the literature that they are not aware of?

Gert: I think that's a fair assessment of what's going on: that probably people are reading much more functionally in terms of what they are looking for, instead of what journals overall represented, which is a cross-section of what's happening in the field. When I look at my own reading habits, I know that I read in this functional way and that it's only on special occasions that I just read because I want to read. And this becomes more difficult compared to journals being a hardcopy collection of a diverse range. Articles today are no longer really visible.

Christoph: Do you think that will also change the direction of journals to specialise more, or do you think that journals will keep their general cross-section of the field?

Gert: It is difficult to say. I do think that the status of journals has become important and that the journals that have a high status - of course we could talk about what criteria are the basis of that status - are actually generic journals. So, I don't see those journals suffering from the change in publication. I also don't see, in the field of education, many niche journals emerging. So from what I can see, the sort of organisation of journals has remained quite stable, which is interesting or remarkable - I have never thought of that. So, I don't see more specialized journals ... but I think that other mechanisms, like the status of a journal, are influencing what is happening.

Christoph: So that ties in with a later question: how do you see the ratings of journals? There is a trend in New Zealand and in many other countries that academics are required to or asked to publish in higher ranked journals, but not everybody can publish there. The ranking means that there is always someone at the top and some are further down. How do you see this in relation to niche journals coming up or the establishment of new journals?

Gert: This is a really difficult issue, because, on the one hand, I see so many new journals being started up for purely commercial reasons that it is important to think about the markers of quality of a journal. Ranking systems are one way of doing this. I don't think that this is ideal, and I know quite a number of countries, which within their own sort of research policies have gone as far as to say: we only accept publications in a particular kind of journal. And then they rely a lot on the Web of Knowledge, Thomson Reuters' citation index, or on similar systems. Sometimes what happens within those countries is that a particular group says: our areas are not present in the system and sometimes they manage to get another set of 
journals on the list. But that always requires extra work and I also know cases were people just said: we need to keep it simple. That begins to marginalize some areas of research. So, on the one hand, because of this proliferation of journals I do think that the question of quality is legitimate and therefore some kind of selectivity is needed, but I don't think that the current systems have in general managed to do that because they are interwoven with national research policies.

One of few countries that have not done something like this is the UK, interestingly. Because the UK has a national system for the assessment of the quality of research, which is done every six or seven years through a big evaluation exercise that is based on each academic submitting their four best publications over a period of six or seven years. The rationale of the approach is that what is being judged is the quality of the research that has been conducted, and publications are seen as a proxy for the research - so it is not a judgment of the quality of the publication itself. And particularly in the field of educational research, the people doing the reviews, and these are peer reviews by about 20 scholars from the UK, have gone against the idea that the journal or the publisher would matter in making the judgment. So they are not looking at any ranking data or statistical data.

Christoph: Going back to online publishing and open-access. What do you think about openaccess journals and how do you see the future of publishing in regards to open-access versus traditional publishing models?

Gert: If by open-access you mean journals that can be accessed by anyone, then I think that is a very good development, on the rather traditional assumption that universities are public institutions, paid from public money, and therefore the publication should be available to the public. So, I think that's the first argument for open-access. I think this argument is gaining momentum. I do know the situation in the UK, where they have introduced policies where they say, for example, that any publication coming out of government-funded research needs to be open-access. So there is no negotiation possible, this is the requirement when you get funding from the funding council you have to do it. Of course, the problem is the commercial side of publishing; so it means then that you need to pay publishers to make your article open-access. What they are charging for that this quite a lot and I expect over time that something will change, either commercial publishers need to change their business model to reduce the costs for profit, or alternative publishing channels will emerge that will gain similar status to what's currently the case within the commercial system.

Christoph: So, are you referring here to "real" open-access or open-source journals that are coming from the community, the academic community, and that are not connected to a commercial publisher?

Gert: Yes, with new open-access, I have in mind any journal where anyone can access the content of the journal, which can be journals from commercial publishers or journals from anywhere else.

Christoph: Traditional publishers have introduced open-access as a mode of 'author-pays', but there are also journals emerging that come from the academic community. Do you see a chance for these journals?

Gert: I am very curious to see what will happen, because I can imagine there will be academic communities that are so strong that, if they set up a journal now and support it, 
within a year such a journal can really have a very high status. I think what commercial publishers have seen quite early on, that it's no longer enough that they just provide the logistics for publishing and distributing. They have invested a lot in all kinds of software to make things available, such as search facilities. What they are trying to do is to say that they are offering an additional service to the academic community. Those infrastructures are pretty expensive, particularly if you look at Taylor and Francis or Springer, for example, they have a global presence, a strong network. For a community of scholars, it is impossible to do something similar. The question is whether in the longer term that infrastructure that publishers are offering will remain important - and I can't predict what will happen. I know that commercial publishers are really trying to make their case the strongest way possible. You can see the pressure from governments that, for example, say that you have to publish open-access if it is publicly funded. That puts pressure on the commercial publishers.

I mean, the downside of it is - and partly I think this is also a question - that there are a lot of entrepreneurs who are currently setting up journals with author fees, simply as a commercial enterprise to see if they can make money out of it. And because of the pressure on people to get their work published, I know that people fall for that option, so that at least it's out somewhere. That is the problematic part of open-access and I don't know where that will go. I find it remarkable that those journals can exist and that apparently there are people who have money to publish in those journals. But because the technology of journal publishing has become widely and freely available, it is very easy to set up your own journal. So, if you really want to get your work out, you can start your own journal. Sometimes I think about the future of academic publishing where everyone has their own journal or publishing blog or something similar.

Christoph: Thinking about the pressure to publish more, the quantity of publishing that is required. What is your opinion on the quality of outputs and future developments?

Gert: Hm, maybe if in terms of development I speak about philosophy of education as an area, I see an increase in quantity, partly because more people are joining the field. I don't think that this in itself is affecting the quality of the work. So just with my own journal, I not only get more manuscripts but they are also of a pretty high standard. So it's not affecting the quality in itself; the only thing I see is that I get more papers that are rather isolated in what they do. They make a point based on a limit set of references. What is suffering, I think, is people spending time on first figuring out what has already been said on a particular topic. In that sense, I see a change in the kind of work, but it's not the quality in itself. Many papers are really good in terms of writing. But people seem to be spending less time on locating their work within the ongoing discussion.

Christoph: Thank you. I think we should move on to another set of questions about the review process. What are your views on the double-blind anonymous peer-review process?

Gert: I am not sure. I'm inclined to say that I think it's a good system. Particularly the double-blindness of it, because it does allow reviewers to really say what they feel they need to say. Although, in a field like ours, which is a fairly small field, and if you know the field relatively well, maybe in forty percent of the cases you can guess who the author is. But still, I think that the double-blind process is a good process, particular from the side of the reviewer. It comes out of a particular culture, or maybe of a particular epistemology, which works very differently in different areas. 
In the sciences, or say social sciences, the purpose of reviewing is quite different from what I see to be the main purpose of reviewing in philosophy of education. So, for example, in quantitative social science studies reviewers need to judge whether the statistics are sound as well as the significant levels and all those kind of things. In a field like philosophy of education, a lot of the reviewing is much more formative, where reviewers judge the quality of an argument, for example. That's what I see a lot of my reviewers do. More even than asking questions about how papers are located within the ongoing discussion. This is a question I actually often need to explicitly ask reviewers: that they pay attention to that as well. It is a different style of reviewing, which has much more to do with judgment, you could say, and a bit less with hard standards. In some quantitative areas, for example, you cannot get your work published in particular journals if your statistical significance is below a certain level. We don't have that in philosophy of education.

So, I think generally it's a good system because it improves the quality of publications. It also helps to consider the general thread of the paper Nick Burbules wrote recently (Burbules, 2014). He wrote a paper on his experience as editor. In a very open way he reflects on all the issues and predicaments of an editor, and one thing he says is that "As Editor, when I see a manuscript, I already know whether it will be published or not; for that I don't need reviewers" - and that is also my experience. Which means the role of reviewers is more that of improving the quality of the argument, for example, and it is less important for the yes/no decision.

Christoph: We spoke about the exponential increase of publications that are coming out; do you see a problem with the double-blind peer review system here?

Gert: The problem is to find people that are willing to review. I know that for myself, because I get many more requests to review papers, I have to say "no" more often. Then I also experience as editor that it is not an automatic "yes" you get from someone when you asked them to review a manuscript. I guess 20 years ago, people would think that this is what you should do, when you get such a request, unless there are exceptional reasons for not doing it. So people are just very busy, which makes it sometimes difficult to get enough reviews of a paper or to have them on time. I can see that the period it takes from submission to decision has become longer over time because it's more difficult to find reviewers. And even the ones who commit, sometimes it drops out of sight in their inbox and they need reminders.

Christoph: What advice do you do give your reviewers for your journal?

Gert: You mean in a general sense or when I communicate with reviewers? I don't use a review team: that may be good to mention. There are journals that have a review board - I just find reviewers for every single script.

Christoph: But are you revisiting reviewers?

Gert: Yes, over time you get to know who are good reviewers and you know who are generous reviewers and who are willing to do it. Those I tend to go back to more. One of the things of being an editor is that you find out things you don't want to find out. For example, that some people are not very good reviewers or very unreliable colleagues. So that is part of how I make a choice. But I always try to look for a good set of reviewers for the particular paper. And then, I just invite them and then I need to rely on what they are willing to do. 
Christoph: And I assume you have some kind of metrics or guide that outlines how to judge this and that aspect?

Gert: Yes, it's quite simple, I have five questions and then I have space for free text and feedback, and I have changed those questions over time. So two points that have become really important for me: pne is whether the paper has sufficient educational focus. Because I take philosophy of education seriously, it has to have to do with education. So if a paper is just making a philosophical point then that is an issue. And the other question I've edited in the list of five is whether the contribution is original, which also means whether the author has made an effort to scan the existing work in the field. And I included those two points because, at some point, it became a problem that I got manuscripts that didn't engage enough with the educational dimension or that did not acknowledge work that had been published already.

Christoph: Where do you draw the line? As we talked about the increase of publications that are out in the world, it gets harder and harder for academics to keep an overview of what has been published already in the field. Where do you draw the line? Is it a quantitative kind of evaluation?

Gert: No, it's not quantitative, but I do want to see in the paper that the author knows where a particular argument is located. And in some cases, it's more important for an argument that it builds upon the existing work and in other cases that's less so. So, I think I make a judgment on that. The other thing I do, and I have been doing that deliberately for quite a while, what for me has always been a big problem in philosophy of education is that authors tend to go back to the philosophers and not to the work of other philosophers of education. And I partly understand why that is the case, but I think it does a disservice to our own field of scholarship, because in a sense it makes what you do invisible in the ongoing development of particular lines. So in very many cases where I give feedback as an editor to an author, I do make this point where I say: you need to include work that has been published by other philosophers of education. And I think I've been successful in changing that. I now see many more references to the work of other philosophers of education. - I think this is really important. I also think it's really stupid when you submit a paper to a journal and have not even looked at what the journal has published on the topic. I had some of those papers that I think I have sent back, just saying: look at what the journal you are submitting the paper to has done in this area, why are you submitting to this journal? Which is a funny criteria, because in the sense that it is not an explicit criteria, but I think it's quite unwise not to do this. It has something to do with whether authors perceive the journal still as a thing, or whether they just see it as a website where you can get stuff published. For me, I've always considered this to be a particular problem in the philosophy of education and I've always tried to alert authors to it.

Christoph: Do you think that reviewers should be paid for the time they spend on reviewing?

Gert: Yes!

Christoph: Do you see that as a possible future development with author-pays and these things in mind?

Gert: I think it's an argument that needs to be made. One way to look at it is how much money publishers make out of journals, even journals in philosophy of education. In that 
sense these journals are not niche. And the mainstream journals are even generating ridiculous amounts of money. However, if we look at it in terms of work, reviewing is work, so why that work should not be compensated is a question. I haven't seen many people making this point. I now make the point when I get invitations from these commercial journals. I just send an email back saying: how much are you going to pay me for reviewing this manuscript? And in most cases I don't get an answer. So, yeah, there is an issue there.

There is probably also an issue in the work of editors, because I know that the work I do as editors is not really compensated in any realistic way - I mean I get a small compensation, but if you see the amount of work I do for it and the responsibility that comes with it, it's not in line. I know that some other journal editors at the moment get much more, but that has to do with the economics of the whole thing. My journal is owned by the publisher and therefore they negotiate fees with editors. EPAT [Educational Philosophy and Theory] is owned by the Society [PESA] and therefore they have very beneficial deals that then also generate money to support the society. So there is a big question about who is actually doing the work and how that work is being compensated. And my position comes out of a much older culture, where being an editor was seen as part of what it meant to be an academic.

Christoph: That would be the next question that comes to mind: what is your motivation? It is not financial: but is it being part of the job, or your passion for the field?

Gert: Well, I think it's partly curiosity. When I was asked to become editor, I was really curious to find out what the process of publishing looked like from the other side, I had no real idea. Partly, it's also an honour to be asked, so that also played a role. And I think, what I've been trying to do is, I have tried to change the identity of the journal, and by doing that you can create opportunities for other kinds of work to be published. So in that sense, as an editor, you can help the field in some way. I think that was another motivation for me. I wanted the journal to do a number of things: broaden the scholarship of philosophy of education, besides I've tested this border between philosophical and empirical work, which I think is an important boarder for us to think about. I probably, but we would need statistics on that, have published a fair share of work from people quite early on in their career, which I find important to do. And I have tried to be diverse in terms of directions and topics. Of course, you rely to a large extent on what people submit to the journal, but over time I have seen that I got more manuscripts that fitted with what I wanted the journal to be. I think people have realised that once a journal publishes a particular kind of manuscripts, people think, "oh that journal is open for that level of work".

Christoph: In terms of the reality of editing and the time that is involved, is there awareness from your employers, so the universities you're working for, that you're editing a journal as part of your time allowance or is it something that's completely on the side?

Gert: In all the places where I've worked as an editor, this has never really been acknowledged. In some cases it has not been acknowledged at all; in other cases, after I have made a very strong case, I've received some support. But even that was quite marginal. I hear from fellow editors who work in North America now that often they get time for doing that, but at European universities, I have never been in a position that I got support from the employers. So in that sense - maybe I'm not a very good negotiator - that could be part of it as well. Because universities do benefit from having those journals edited by their staff. 
However, they have never been proactively saying: we will make sure you have time for editing.

Christoph: Moving on to early career academics. In addition to the points we covered above, what advice would you give early career academic researchers if they want to publish in your journal?

Gert: I think the general advice I would give is: try to understand the journal; try to figure out what it is about, what it tries to do; and make sure that what you submit fits the intention of the journal, which also means to honour what the journal tries to do. So make sure that you check in the journal whether there have been any relevant publications. That's partly because I think it is important for philosophy of education to build on its own achievements, and it's partly because editors are human beings and they can get irritated if they get papers where they can see that the authors have not made a real effort to think about why they are submitting to their journal. So, it's also a matter of communication.

The other thing I would advise anyone, but particular early career researchers, is to try to communicate well with the editor. Not too much, but make it pleasant and be clear particularly when you get into the process of revisions. What I find very helpful is that, when authors submit a revised manuscript, they explain to me what they have done. I don't expect that people just follow everything in the feedback from the reviewer - I want them to make a judgement, but I want to see that judgement. So, it's also partially about making the life of an editor as easy as possible. Good communication is, I think, the main tip I would give to early career researchers.

Christoph: How has being an editor changed your career?

Gert: That's a funny question! I think it has helped me getting to know many more people in the field. You get a broader overview of what people are doing. You understand better what they are doing and how committed they are. I think, what I also have enjoyed is having that interaction with a wide group of people in the field. Whether that has changed my career is difficult to say; it simply means that as an editor you get a bigger network. I am not sure if it has given me any particular opportunities, but it has made the task more enjoyable in that sense. I don't think it has damaged my career; although, there must be people out there that were pretty upset about a rejection that was sent to them. And maybe in some cases, when looking for a new job, the editorship was an important element on my CV. That's roughly how it has had an impact.

Christoph: Thank you. Next topic. At this time all the major journals in philosophy of education are edited by men. What is your opinion on that?

Gert: Yes, good question. I think this is a bad situation, and I said in public about five years ago at a symposium we had at the American Philosophy of Education Society that if it were up to me, I would do anything possible to make sure that the next editor of my journal would be a woman. And I am going to step down next month [January 2015] and the next editor is a woman. So I am really glad that I've managed to do that. So, I thought this was just a very bad situation that should have been changed a long time ago. 
Christoph: Oh, that is great! We are moving on to the last questions. What characteristics distinguish publishing work in philosophy of education from other fields and areas of educational research in your view?

Gert: This is quite a complicated question. But I do understand that the situation, the status of philosophy of education is very different in different countries. In the Netherlands it is really a problem, and it is one of the reasons why I left the Netherlands, because there was such a low status for that kind of work. I understand that in a particular context this is an issue. During my editorship, I managed to get the Journal into the Social Science Citation Index. While I think that those indexes are not a good idea, because they are too excluding, I do know that this is important for people's careers in particular countries. I felt that this was one of the few ways in which the people who were always arguing that philosophy of education is by definition inferior - that this would convince them by saying "Well, we play in the same league and we play according to the same rules, but we do different things". So, it's a really difficult discussion, because some people have negative views about philosophy of education, and I thought the only way to convince them is to show that if we stick to the same rules, we can achieve the same things, and we are doing the same work at the same level. So, that's why getting into the index was important for me.

Christoph: OK, but what is it that we do different in philosophy of education? Are you comparing here to sciences or to other areas in the humanities?

Gert: I compare it to the broader field of educational research, so to empirical work either quantitative or qualitative. In the Netherlands, the battle was that people would say that only quantitative work is serious science, the rest is just opinion. So qualitative work suffered from it, philosophy of education suffered from it.

Christoph: This is an interesting view for Europe, I would say.

Gert: Yes, I think it's becoming more influential in other countries as well; Belgium suffers from it, for example. So, this has a lot to do with local or national politics. In Britain, I haven't perceived it in that way. I have seen a lot of qualitative research there that is representing the field and is mainstream educational research, I would say.

Christoph: What are your thoughts about the disadvantages and advantages our field in particular faces in terms of existing or anticipated metrics you are most familiar with?

Gert: I think there are a couple of dimensions with regard to metrics. One is the impact factor, which is important in some countries, and one of the disadvantages of how it is calculated in Thomson Reuters is that it relies on speed. So, they look at citations of a paper in the first 24 months after it has been published. That whole thinking about the impact comes from high-speed disciplines, like the natural sciences, where the job is to make new discoveries, for example. So those are very quick cycles. That cycle is, I think, almost irrelevant in philosophy of education because the cycles are much slower and the point is not to replace all knowledge with new knowledge but to add to existing arguments. So that's a problem with the impact factor, that it comes out of a natural science logic, and that can disadvantage the philosophy of education.

But this is also one of the reasons why I insist on quoting other philosophers of education, because that's the only way in which impact factors can go up and at least we can play that 
game. But the length of the cycle is a problem. The other important metric is citations, which is another good reason for citing the work of other philosophers of education, because Plato doesn't need more citations, but you do and maybe I need a little of them but not that much. So, simply for, you could say, the position of philosophy of education within the wider field of educational research, it is really important that we use each other's work. Otherwise, within these metrics we keep it at the low end.

Christoph: That is very interesting for me! The question that we half-skipped earlier, in relation to these metrics and rankings of journals, is the question of what criteria should be applied to judge journals. Not to rank them, but to judge the quality of the philosophy of education journals?

Gert: For me, peer-review would be an important criterion, and I guess that transparency of peer-review might become important. So that we not simply say everything is peer-reviewed, but that we also show who the peer-reviewers are. That allows people to make a judgement about the status in the field. I also think that a journal that charges for publication would only be at the very bottom end of the spectrum. But this is different from charging for open-access, because then it has gone through a whole review process. Apart from that, I'm not sure.

I think there is also the question whether, say, work that is relevant in a particular way should be ranked more highly, like work that deals with current urgent problems, or something like that. I don't feel that that should be an issue in any field and also not in philosophy of education. So, I would expect the logic of the field in itself here, and if it wants to deal with problems that may seem irrelevant in relation to contemporary policy, that's fine as well, that's what the field should decide.

Christoph: OK, thank you. So what advice about choosing an avenue for publication would you give specifically to early career researchers and higher degree students wanting to establish a profile?

Gert: Hm, that's a difficult question, because on the one hand I would say don't start too soon and work on writing really good papers. On the other hand, I know from my own career that I started too early and I have benefited from it as well. Because by doing that you also begin to understand what it means to write, what it means to publish and all that. And I think what I did in my own career is starting by trying to get things published and then gradually try to get it published in better places, more and more visible places. Whether that still is good advice in the current publishing environment, I don't know.

I think my advice would be to try to do something that's really good, so you invest a lot of time in the quality of your scholarship, before you try to get published. But once you have developed a good area of scholarship, then you should be quite strategic in publishing. Which not only means that you should try to publish in good places that give you visibility, but one thing that people should also acknowledge is that quantity has also become important in the current publishing environment. In the past you could make a career with maybe two really good papers; now, in order to be noticed, you probably need to have twenty papers in different journals, conferences, etc. So, simply in order for the work become visible, the quantity is a factor... which is sad advice to give, but I think that is what it is.

Christoph: OK, so for me, being in a position of an early career academic, to become visible what you would say is to publish strategically over a broad range of journals? 
Gert: Yes, different journals - conferences are important as well, because they are also about mutual peers. I think, broadly what I've always done, but maybe that's my specific profile, I haven't confined myself to philosophy of education journals. So really, I see myself more as sort of an education scholar who is interest in theory and philosophy; I really try to get my work out in a wide range of journals, which has helped me for the particular things I wanted to do.

Christoph: And have you been able to publish philosophical topics in general education journals?

Gert: Yes, I think so. I also think that journals are more open to philosophical work than maybe some people realise. So journals in curriculum studies, for example - that is also a whole field where good theoretical and philosophical work can have a place if it also engages with questions of curriculum.

Christoph: OK, do you have any other comments you would like to make at the end?

Gert: No, not really, no. I think this is an interesting project you are doing, and I am curious about what you all will write.

Christoph: Thank you very much, Gert!

Gert: Welcome.

\section{Conclusion}

In this interview, Biesta shared his experiences over the last 18 years around some of the larger developments that took place in the publishing world, especially in the area of philosophy of education. Some of the most exciting developments have been around online publishing, open-access, and in a current shift towards nominating more women into leading editorial positions for philosophy of education journals. Another shift that affects especially early career academics is the significant increase in publications worldwide. To be noticed as an emerging researcher today, one has to publish significantly more articles of high standard than 15 or 20 years ago. Therefore, one suggestion Biesta makes is to think beyond the boundaries of philosophy of education and to publish articles in other educational journals, such as curriculum topics or journals that have a wider educational focus. We also touched on some of the challenges for the field of philosophy of education and Biesta pointed out the importance of situating new articles and current work not only historically with references to philosophers such as Plato or Aristotle but rather in current lines of thought and areas of research. Especially in light of the current emphasis on journal rankings and impact factors, drawing on and referencing recent articles from educational philosophers is important to strengthen the field of educational philosophy and theory as a whole. Thank you again, Gert Biesta, for making time for this interview.

\section{References}

Burbules, N. (2014). Philosophical Reflections on Editing. Educational Theory, 64(4), 317331. 